\title{
RADIOLOGICAL AND ENDOSCOPIC FINDINGS IN 50 CASES OF RECURRENT SINUSITIS UNDERGOING REVISION ENDOSCOPIC SINUS SURGERY
}

\author{
J. P. Goyal' ${ }^{1}$ Amit Gupta², Imrinder Kaur ${ }^{3}$ \\ ${ }^{1}$ Associate Professor, Department of ENT, Government Medical College, Patiala. \\ 2Junior Resident, Department of ENT, Government Medical College, Patiala. \\ ${ }^{3}$ Senior Resident, Department of ENT, Government Medical College, Patiala.
}

\begin{abstract}
\section{BACKGROUND}

Postsurgical sinonasal disease can be attributable to a number of conditions such as scar formation with ostial obstruction, impaired mucociliary flow, retained ethmoid air cells, retained ethmoid septae, osteoneogenesis, or primary mucosal membrane disease. Understanding these conditions allows for more precise treatment.
\end{abstract}

\section{MATERIALS AND METHODS}

A study of 50 patients with recurrent sinusitis who underwent revision endoscopic surgery during 2011-2013 was conducted. All the patients with chronic sinusitis had previous sinus surgery, did not respond to medical treatment, and underwent revision endoscopic sinus surgery after CT scanning of paranasal sinuses and diagnostic nasal endoscopy. The different sinonasal anatomical variations that may predispose an individual to persistent or recurrent sinonasal disease were studied.

\section{RESULTS}

The major causes for recurrence in our study were found to be residual uncinate process (86\%), bulla ethmoidalis disease (anterior ethmoid cells; 90\%), and frontal recess blockade (92\%). Other significant anatomical variations noted were septal deviations (16\%), inferior turbinate hypertrophy (50\%), concha bullosa (32\%), supraorbital cells (8\%), and accessory maxillary sinus ostia (15\%).

\section{CONCLUSION}

According to our study, the major reasons for failure of primary surgery were the failure to address the various anatomical variations of the nose during surgery and the failure to remove complete pathology. These issues were addressed during the revision surgery, which was found to have a good prognosis when performed successfully.

\section{KEYWORDS}

Recurrent Sinusitis, Revision Endoscopic Sinus Surgery.

HOW TO CITE THIS ARTICLE: Goyal JP, Gupta A, Kaur I. Radiological and endoscopic findings in 50 cases of recurrent sinusitis undergoing revision endoscopic sinus surgery. J. Evolution Med. Dent. Sci. 2016;5(97):7101-7104, D0I: $10.14260 /$ Jemds/2016/1608

\section{BACKGROUND}

Chronic sinusitis is a clinical disorder that encompasses a heterogenous group of infectious and inflammatory conditions affecting the paranasal sinuses. It is repeated bouts of acute infection or persistent inflammation of sinuses. Chronic sinusitis and chronic sinusitis with nasal polyps comprise a variety of disorders that cause inflammation of the sinonasal mucosa. It affects men and women equally, but subtypes of chronic sinusitis appear to have different gender distributions. ${ }^{1}$

The clinical diagnosis of chronic sinusitis is somewhat difficult, due to difficulty in defining the disease and a variety of presenting signs and symptoms. American Academy of Otolaryngology-Head and Neck Surgery(AAO-HNS) Task Force criteria to define and diagnose chronic sinusitis are based on the presence of two or more major factors or one major and two minor factors. These signs and symptoms

Financial or Other, Competing Interest: None.

Submission 14-11-2016, Peer Review 26-11-2016,

Acceptance 29-11-2016, Published 05-12-2016.

Corresponding Author:

Dr. J. P. Goyal,

D-10 Medical Campus Rajindra Hospital,

Patiala.

E-mail:drjpgoyal4@gmail.com

DOI: $10.14260 /$ jemds/2016/1608 should have lasted for $>12$ consecutive weeks or $>12$ weeks of physical findings. Importantly, the Sinus and Allergy Health Partnership (SAHP) 2003 also incorporates computed tomographic (CT) imaging of the sinuses and endoscopy for confirming the diagnosis. ${ }^{1}$ Major factors include facial pain/pressure, nasal obstruction/ blockage, nasal discharge/ purulence/discoloured postnasal drainage, hyposmia/anosmia, and purulence in nasal cavity on examination. Minor factors include headache, fever, halitosis, dental pain, cough, and ear pain/pressure/fullness. ${ }^{1}$

The current imaging study of choice is a fine coronal cut CT of the sinuses. To carry out the surgery on frontal sinus Keros classification is required for which coronal view of CT scan are preferred over other views. ${ }^{2}$ CT provides a roadmap for endoscopic sinus surgery, spots potential complications from bony dehiscence in the skull base or orbit, and identifies mucosal thickening and trapped secretions within the paranasal sinuses. ${ }^{3}$ A slice thickness of $3 \mathrm{~mm}$ and a scan plane within $10^{\circ}$ perpendicular to the hard palate best display the ostiomeatal unit. 4

All cases of chronic sinusitis are associated with anatomical variations and/or pathological abnormalities of the "ostiomeatal area" that are responsible for persistent infection in the ethmoid and their dependent sinuses. 5

Nasal endoscopes allow a very thorough inspection in the office setting with minimal discomfort to the patient. It allows 
the assessment of mucosal hyperaemia, oedema, the gross appearance and sites of origin of nasal polyps, and septal deformities or other abnormalities impacting sinus drainage. ${ }^{1}$ Postsurgical sinonasal disease can be attributable to a number of conditions, such as scar formation with ostial obstruction, impaired mucociliary flow, retained ethmoid air cells, retained ethmoid septae, osteoneogenesis, or primary mucosal membrane disease. Understanding these conditions allows a clinician to prescribe a more precise treatment.

In the years since endoscopic sinus surgery was introduced, the approach to sinonasal disease has changed dramatically. Initially, only a select group of otolaryngologists was treating patients with endoscopy; currently, it is the standard of care. Education and training have centred on the unoperated patient. However, surgeons are being asked to treat an increasing number of patients who have had previous sinus surgery. The approach in revision surgery can differ because many of the normal anatomic landmarks used to guide the initial surgical dissection are missing in these patients. In addition, persistent longstanding inflammation and fibrosis can create further surgical challenges. Revision endoscopic sinus surgery requires recognition and removal of recurrent or residual chronic sinus disease while avoiding complications. ${ }^{6}$

\section{MATERIALS AND METHODS}

The study entitled Radiological and Endoscopic Findings in 50 Cases of Recurrent Sinusitis Undergoing Revision Endoscopic Sinus Surgery was conducted in the Department of Ear, Nose, Throat (ENT), Government Medical College and Rajindra Hospital, Patiala, Punjab, India.

\section{Source of Data}

All the patients admitted in the ENT Department of Rajindra Hospital with proven history of recurrent sinusitis not responding to medical treatment with full course of antibiotics, analgesics, and decongestants; who already had a surgical intervention performed; and who underwent revision endoscopic sinus surgery after CT scanning of paranasal sinuses and diagnostic nasal endoscopy were selected. The sample size was 50 .

\section{Inclusion Criteria}

All the patients with chronic sinusitis who had previous sinus surgery, not responding to medical treatment, and willing to undergo revision endoscopic sinus surgery and CT scanning of paranasal sinuses.

\section{Exclusion Criteria}

1. Patients who had previously undergone only septal or turbinate surgery.

2. Patients with chronic sinusitis responding to medical management.

3. Patients not consenting to participate in the study.

\section{Data Collection}

The cases selected for the study were subjected to detailed history taking and evaluation. Routine investigations such as haemogram and routine urine evaluation were carried out. Those patients in active stage of the disease were treated with a course of antibiotics, analgesics, and decongestants. On Diagnostic Nasal Endoscopy, those patients who had nasal polyposis received a short course of steroid therapy. ${ }^{7}$ The patients underwent standard three-pass diagnostic nasal endoscopy using $0^{\circ}$ and $30^{\circ}$ Hopkins rod telescopes. The patients also underwent CT scanning of paranasal sinuses (coronal view). Finally, the patients underwent endoscopic sinus surgery, the extent of which was dictated by the disease extent defined by the above diagnostic procedures.

\section{RESULTS}

\section{The Findings that were Recorded in our Study were}

1. Septal deviations were observed in $16 \%$ cases with preponderance of deviation to the left $(62.5 \%)$ compared to deviation to the right (37.5\%).

2. The prevalence of septal spurs was $8 \%$. Among these, $50 \%$ had contact with the turbinates.

3. Agger nasi cells were found in $70 \% ; 80 \%$ of these cells were bilateral.

4. Frontal cells were observed in 22 sides. Of these, $15 \%$ were of type I, $2 \%$ of type II, $2 \%$ of type III, and $3 \%$ had type IV frontal cells.

5. Prevalence of nonpneumatisation of frontal sinus was found to be $8 \%$.

6. Frontal recess was obstructed in $92 \%$ sides. Of these, in $70.23 \%$, the obstruction was by agger nasi cells, in $16.67 \% \%$ by frontal cells, and in $13.09 \%$ by polyps.

7. The middle turbinate was pneumatised in $32 \%$, medialised in $5 \%$, lateralised in $6 \%$, hyperplastic nonpneumatised in $4 \%$, and paradoxically curved in $2 \%$ patients. Of the patients with pneumatised middle turbinates, $31.25 \%$ showed lamellar pattern, $25 \%$ showed bulbous pattern, and $43.75 \%$ showed true concha bullosae.

8. Residual disease in bulla ethmoidalis was present in $90 \%$ cases.

9. Superior attachment of uncinate process to lamina papyracea was observed in $69 \%$ sides, to skull base in $14 \%$ sides, and to middle turbinate in $3 \%$ sides. Its definite attachment could not be determined in $14 \%$ sides.

10. The uncinate process was typical in $46 \%$, medialised in $36 \%$, anteriorly turned in $4 \%$, lateralised in $8 \%$, hypertrophied in 3\%, and pneumatised in 3\% sides.

11. Maxillary sinus septa were observed in $4 \%$ sides.

12. The accessory ostia of the maxillary sinus were present in $15 \%$ nasal cavities. Anterior fontanelle $(10 \%)$ was present more often than posterior fontanelle (5\%).

13. We found inferior turbinate hypertrophy in $50 \%$. Of these, the hypertrophied inferior turbinate was associated with ipsilateral maxillary sinus pathology in $70 \%$.

14. The prevalence of superior turbinate pneumatisation was $7 \%$.

15. The presence of supreme turbinate in any of our cases could not be discerned.

16. Onodi cells were observed in $17 \%$ sides.

17. Haller cells were present in $5 \%$ sides.

18. Supraorbital ethmoidal cells were present in $8 \%$ sides.

19. Nonpneumatised sphenoid sinus was absent in $2 \%$, conchal type in $2 \%$, presellar type in $32 \%$, and sellar in $64 \%$ cases.

20. Intrasphenoid projections were as follows: Optic nerve in $27 \%$, maxillary nerve in $34 \%$, and vidian nerve in $29 \%$ sides.

21. Skull base depth was recorded as follows: Keros type I (1$3 \mathrm{~mm}$ deep) olfactory fossa in 14\%, type II (4-7 mm) in $70 \%$, and type III (8-16 mm) in 16\% nasal cavities. 


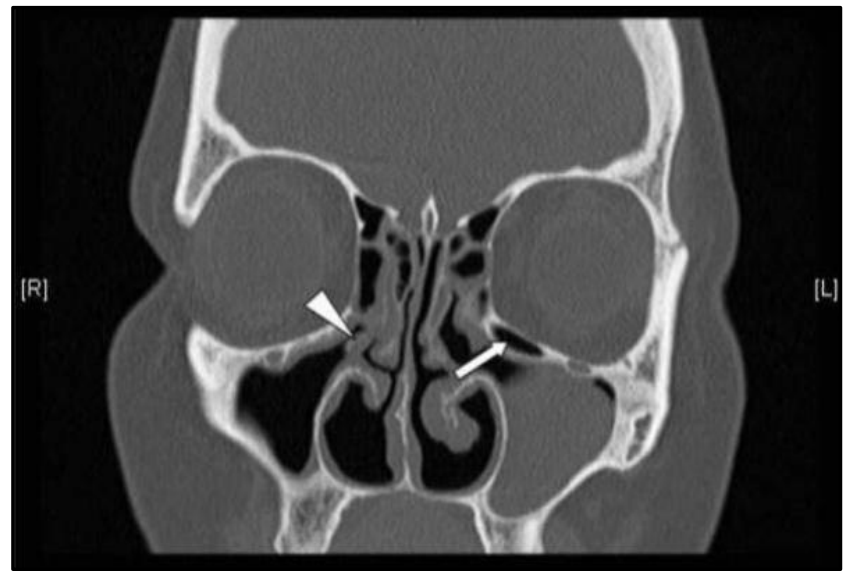

Figure 1. Residual uncinate process and anterior ethmoidal cells. A coronal CT scan of a patient admitted for revision functional endoscopic sinus surgery (FESS) showing a residual right uncinate process (arrowhead) and residual anterior ethmoid cells (arrows)

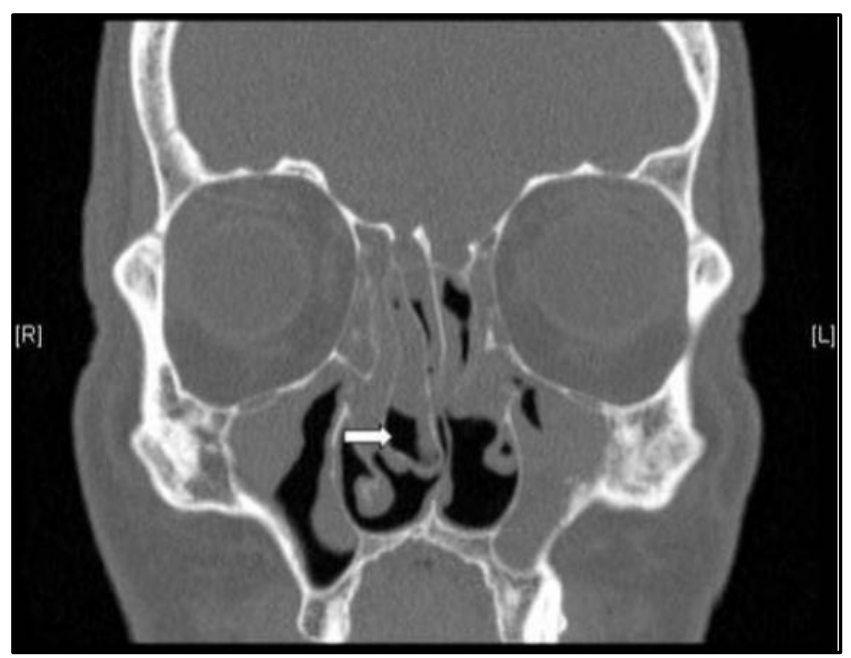

Figure 2. Residual large right concha bullosa. A coronal CT scan of a patient admitted for revision FESS showing a residual large right concha bullosa (arrow)

\section{DISCUSSION}

In this study, a total of 100 nasal cavities were examined by diagnostic endoscopy, CT scan and at the time of definitive surgery. We found septal deviation in $16 \%$ of cases. The prevalence of deviation of nasal septum as reported by various workers: $21 \%$ Zinreich et al 19878; 18.8\% Bolger et al 19919; $36 \%$ Arslan et al 1999.10 The mere presence of septal deviation does not suggest pathology. However, a marked deviation can force the middle turbinate laterally thus narrowing the entrance to middle meatus. The prevalence of agger nasi cells was seen in $70 \%$. It varies widely as reported by various workers: $10-15 \%$ Messerklinger 196711; 40\% Dua et al 200512; 86.7\% Tonai and Baba 199613; 98.5\% Bolger et al $1991^{9}$ and $100 \%$ Zinreich et al 19878 . In a study by Musy and Kountakis, retained agger nasi cells were seen in $49 \%$ of the cases of revision surgery. ${ }^{14}$ Frontal cells are derived from anterior ethmoid cells behind the agger nasi cells and they pneumatise the frontal recess above the agger nasi cells. Frontal cells were found in 22 sides. Of these, 15 were of type I (15\%), 2 of type II (2\%), 2 of type III (2\%), and 3 of type IV (3\%) which are approximately comparable to the studies of
Meyer et $\mathrm{al}^{15}$ \& Woo et $\mathrm{al}^{16} \mathrm{We}$ found the prevalence of nonpneumatisation of frontal sinus in $8 \%$. This is slightly higher than the study by Natsis et al 17 who reported a prevalence of $5 \%$. The frontal recess was found to be obstructed in $92 \%$ cases. It was caused mainly by agger nasi cells, residual frontal recess cells, and polyps. As opening the agger nasi cells usually provides a good view of the frontal recess, therefore, identification of this variation is important in diagnosis and treatment of recurrent or chronic frontal sinusitis. Our results of pneumatised middle turbinate are close to that reported by Arslan et $\mathrm{al}^{10}$ in the setting of recurrent sinus disease resection of concha bullosa should be considered to improve the paranasal sinus access and ventilation. An enlarged bulla can result in a narrow hiatus semilunaris. We found a large ethmoidal bulla in $90 \%$ cases. Residual uncinate process was identified in $86 \%$ patients. In our study, we found medially turned uncinate process in $37 \%$. This correlates well with $42.27 \%$ deviation reported by Liu et al ${ }^{18}$ and $31 \%$ deviation reported by Danese et al. ${ }^{19}$ According to our study, the residual uncinate process was one of the major causes of failure of primary surgery. Our study of maxillary sinus septa in $4 \%$ of sides is comparable to the study of Dua et al ${ }^{12}$ i.e. $6 \%$. Maxillary septa cause impaired drainage in part of maxillary sinus. We found inferior turbinate hypertrophy in $50 \%$. Our finding of superior turbinate pneumatisation of $7 \%$ correlates to the prevalence of marked pneumatisation reported by Ariyurek et al. ${ }^{20}$ Markedly pneumatised superior turbinates can narrow the nasal cavity predisposing the patient to recurrent sinusitis. In our study, the prevalence of Onodi cells was $17 \%$. The prevalence of Onodi cells according to Aibara et al ${ }^{21}$ was $7 \%$. In our study, accessory ostia were present in $15 \%$ of nasal cavities. Ramadan ${ }^{22}$ had also reported accessory ostia in $15 \%$ cases having revision surgery. Accessory maxillary sinus ostia when present cause recirculation of maxillary sinus mucus. When these ostia are not addressed during primary surgery, they contribute to recurrence of disease. Other significant anatomical variations that were noted were Haller cells (5\%) and supraorbital cells (8\%). Supraorbital cells can cause obstruction in the frontal recess region.

\section{CONCLUSIONS}

It can be concluded that the major reasons observed for failure of primary surgery were a failure to perform a complete uncinectomy, a failure to remove the disease completely from the ethmoid system, and also a failure to clear the frontal recess region, which in many cases was due to an inability to clear the agger nasi cells. Other anatomical variations such as inferior turbinate hypertrophy, concha bullosa, supraorbital cells, and accessory maxillary sinus ostia also played a role in the recurrence of the disease. The major causes of recurrence in our study were residual uncinate process, disease in the bulla ethmoidalis and frontal recess blockade which correlate with the similar studies. In view of the presence of these significant variations, we emphasise that endoscopic surgery is beneficial to the previous types of sinus surgery, and there is a need of preoperative assessment in every patient in order to accomplish a safe and effective endoscopic sinus surgery, any failure to do so will lead to an unsuccessful surgery and recurrence of disease. 


\section{REFERENCES}

1. Schlosser RJ, Woodworth BA. Chronic rhinosinusitis and polyposis. In: Snow B, Wackym PA. 17th edn. Ballenger's otorhinolaryngology. PMPH: USA 2008:573-83.

2. Kaplanoglu H, Kaplanoglu V, Dilli A, et al. An analysis of the anatomic variations of the paranasal sinuses and ethmoid roof using computed tomography. Eurasian J Med 2013;45(2):115-25.

3. Snow JB, Wackym PA, Ballenger JJ, et al. Ballenger's otorhinolaryngology head and neack surgery. $17^{\text {th }}$ edn. London: BC Decker Inc 2009.

4. Melhem ER, Oliverio PJ, Benson ML, et al. Optimal CT evaluation for functional endoscopic sinus surgery. Am J Neuroradiol 1996;17(1):181-8.

5. Stammberger H, Posawetz W. Functional endoscopic sinus surgery. Concept, indicators and results of the Messerklinger technique. Eur Arch Otorhinolaryngol 1990;247(2):63-76.

6. Zinreich SJ, Gotwald T. Diseases of the sinuses: diagnosis and management. PMPH-USA 2001;611:13-29.

7. Lildholt T, Runderantz H, Bende M, et al. Glucocorticoid treatment for nasal polyps. The use of topical budesonide powder, intramuscular betamethasone, and surgical treatment. Archives Otolaryngology Head Neck Surgery 1997;123(6):595-600.

8. Zinreich SJ, Kennedy DW, Rosenbaum AE, et al. Paranasal sinuses: CT imaging requirements for endoscopic surgery. Radiology 1987;163(3):769-75.

9. Bolger WE, Butzin CA, Parsons DS. Paranasal sinus bony anatomic variations and mucosal abnormalities: CT analysis for endoscopic sinus surgery. Laryngoscope 1991;101(1 Pt 1):56-64.

10. Arslan H, Avdinlioglu A, Bozkurt M, et al. Anatomic variations of the paranasal sinuses: CT examination for endoscopic sinus surgery. Auris Nasus Larynx 1999;26(1):39-48.
11. Messerklinger W. On the drainage of the normal frontal sinus of man. Acta Otolaryngol 1967;63(2):176-81.

12. Dua K, Chopra H, Khurana AS, et al. CT scan variations in chronic sinusitis. Ind J Radiol Image 2005;15(3):315-20.

13. Tonai A, Baba S. Anatomic variations of the bone in sinonasal CT. Acta Otolaryngol 1996;525:9-13.

14. Musy PY, Kountakis SE. Anatomic findings in patients undergoing revision endoscopic sinus surgery. Am J Otolaryngol 2004;25(6):418-22.

15. Meyer TK, Kocak M, Smith MM, et al. Coronal computed tomography analysis of frontal cells. Am J Rhinol 2003;17(3):163-8.

16. Woo JK, van Hasselt CA, Tong MC. Treatment results of sinonasal inverted papilloma: an 18-year study. American journal of rhinology \& allergy 2009;23(2):203-11.

17. Natsis K, Karabatakis V, Tsikaras $P$, et al. Frontal sinus anatomical variations with potential consequences for the orbit. Study on cadavers. Morphologies 2004;88(280):358.

18. Liu X, Zhang G, Xu G. Anatomic variations of the ostiomeatal complex and their correlation with chronic sinusitis: CT evaluation. Zhonghua Er Bi Yan Hou Ke Za Zhi 1991;34(3):143-6.

19. Danese M, Duvoisin B, Agrifoglio A, et al. Influence of nasosinusal anatomic variants on recurrent, persistent or chronic sinusitis. X-ray computed tomographic evaluation in 112 patients. J Radiol 1997;78(9):651-7.

20. Ariyurek OM, Balkanci F, Aydingoz U, et al. Pneumatised superior turbinate: a common anatomic variation? Surg Radiol Anat 1996;18(2):137-9.

21. Aibara R, Kawakita S, Yumoto E, et al. Relationship of onodi cell to optic neuritis-radiological anatomy on coronal CT scanning. Nippon Jibinkoka Gakkai Kaiho 1997;100(6):663-70.

22. Ramadan HH. Surgical causes of failure in endoscopic sinus surgery. Laryngoscope 1999;109(1):27-9. 